on a firm. Though time lost through sickness does not achieve the publicity given to time lost through strikes it accounts for perhaps $\mathbf{3 0}$ times as many lost days as strikes do.

Absence due to sickness is rising steadily in Britain, but this is not necessarily another symptom of our industrial malaise. The increase lags behind-thankfully for a changethat observed in some other Western industrial countries such as Holland and Sweden. The O.H.E. pamphlet suggests that the increase may be related to greater affluence and lower sickness thresholds, and possibly a greater professional and public acceptance of neuroses as respectable reasons for stopping away from work, though the rise in the diagnosis of neuroses is partially offset by a fall in other diseases-for instance, tuberculosis-as a cause of absence.

Job satisfaction is the factor which the O.H.E. sees as particularly significant. It is, furthermore, one that is probably more susceptible to control than individual health, childhood neuroses, or domestic circumstances, which are other relevant and obvious influences shown in recent studies. Thus, as the pamphlet suggests-and this has been referred to in these columns before ${ }^{2}$-"one of the keys to the minimization of sickness absence, particularly short-term absence, is in the hands of management." The possibility that the incidence of unofficial strikes may also be related to dissatisfaction with work as well as with levels of pay suggests that some urgent wide-scale studies on job satisfaction are needed. They would not be easy to conduct, but if the results of unofficial strikes and of sickness absence on the country's economy are as serious as is often suggested it would be well worth the money and effort required to carry them out effectively.

The B.M.A. has consistently supported the setting up of a national occupational health service and was disappointed because the Government's establishment recently of the Employment Medical Advisory Service was seen as only a small step towards a comprehensive scheme. Obviously better co-operation between N.H.S. doctors, especially general practitioners, and occupational health doctors is urgently needed to assist the individual patient as well as the national economy. Integration of the N.H.S. should also help. Whether the large-scale expansion of individual occupational health services, with the transfer of some preventive medicine and family doctoring to the factory as suggested by the O.H.E., is a realistic solution is debatable. Apart from the special place which the general practitioner holds in medical care in Britain, a large number of people work in small firms or scattered units which could not hope to provide the facilities necessary for an effective service. Furthermore, the conurbations with their worsening commuter problems present special difficulties in the continuity of health care. The risks of overlaps and gaps in such a firm-orientated scheme, even with an integrated health service, would outweigh any advantages it might produce.

However, the O.H.E.'s pamphlet deserves to be read by doctors, management, and Government, and it should prompt some informed discussion of sickness absence. Perhaps the National Health Service itself could show the way by providing a comprehensive occupational health service for its staff, and the Civil Service, as a large and well documented work force is a ready-made guinea pig for a large-scale study of why people go off sick. The Government has a double interest in the problem as employer and because of its role in the economy. It is also well placed to take the lead in developing research and initiating pilot experiments.

\footnotetext{
1 Office of Health Economics, Off-Sick. London, 1971.

- British Medical fournal, 1970, 3, 192.
}

\section{Atrial Myxoma}

Myxomas are the commonest cardiac tumours, accounting for about half the total. Slow-growing and benign, these gelatinous growths usually arise from the interatrial septum in the region of the fossa ovalis. In most cases they are pedunculated. They occur twice as commonly in the left atrium as in the right, slightly more often in women, and usually in the fourth, fifth, or sixth decades.

The clinical picture can mimic many diseases, but effort dyspnoea is a frequent symptom, and the patient usually gives a history of constitutional disturbance which often extends for many months previously. Features include loss of weight, fatigue, low-grade fever, joint pain, polyneuritus, anaemia, anorexia, nausea, and palpitations. Further clinical features are related to embolism or to obstruction, though both are rare in the case of right-sided tumours; it is possible that many pulmonary emboli are silent and not diagnosed. When obstruction is a feature the patient presents with a history of sudden syncopal attacks, probably caused by the pedunculated tumour moving to block blood flow through the tricuspid valve. This movement of myxomata in the right atrium has led to the use of the term "the wrecking ball," by analogy with the iron ball used to destroy old buildings. ${ }^{12}$

On clinical examination a patient with a right atrial myxoma has tachycardia, prominent venous pulsation in the neck, and a systolic murmur maximal to the left of the lower sternal edge, increasing during respiration and frequently not extending throughout systole. In addition there may be a soft diastolic murmur with presystolic accentuation, and a rightsided third heart sound is often present. These signs are frequently variable, and in several reported cases the intensity of the murmurs has varied between examinations. ${ }^{34} \mathrm{~J}$. B. Hickie, H. Gibson, and H. M. Windsor ${ }^{2}$ reported a widely split first heart sound in one patient; an early systolic sound, varying in intensity, heard at the lower left sternal border has been described by several authors and named "systolic tumour sound" by C. E. Martin and colleagues. ${ }^{3} \mathrm{G}$. Kaufmann and colleagues ${ }^{5}$ also noted the wide splitting of the first heart sound and considered that right and left atrial myxomas could be distinguished on the basis of the second heart sound; the two components tended to fuse when the tumour was on the right side and to be widely separated with left atrial myxoma.

Laboratory investigations show an elevated sedimentation rate and high serum globulin levels. This general disturbance has been attributed to necrosis of the tumour itself $^{6}$ or to an autoimmune response.?

Electrocardiographic changes are variable and arrythmias are uncommon. The $\mathbf{P}$ waves are often prominent and right bundle branch block is commonly seen. The chest radiograph often shows enlargement of the right atrium, and calcification of the tumour is sometimes a striking finding. ${ }^{389}$ Cardiac catheterization shows evidence of tricuspid incompetence, some elevation of pulmonary arterial pressure, and occasionally a small left to right shunt.10 Venous angiography is diagnostic, and G. C. Oliver and G. A. K. Missen ${ }^{8}$ comment that a diagnosis of Ebstein's anomaly should never be made until right atrial myxoma has been excluded by angiography.

The importance of a correct diagnosis is emphasized by the excellent results obtained from surgical excision of the tumour. $^{279}$ Since right atrial myxomata can be completely 
removed and the patient restored to normal health with little surgical risk, full investigation and angiography should be carried out whenever this diagnosis is considered.

1 Harvey, W. P., American fournal of Cardiology, 1968, 21, 328.

2 Hickie, J. B., Gibson, H., and Windsor, H. M., Medical fournal of Australia, 1970, 2, 82

3 Martin, C. E., Hufnagel, C. A., and de Leon, A. C., American Heart fournal, 1969, 78, 245.

Wight, R. P., McCall, M. M., and Wenger, N. K., American fournal of Cardiology, 1963, 11, 790.

- Kaufmann, G., Rutishauser, W., and Hegglin, R., American fournal of Cardiology, 1961, 8, 350 .

- MacGregor, G. A., and Cullen, R. A., British Medical fournal, 1959, 2,

991 .
Currey, H. L. F., Mathews, J. A., and Robinson, J., British Medical fournal, 1967, 1, 547.

Oliver, G. C., jun., and Missen, G. A. K., Guy's Hospital Reports, 1966,

115, 37. C., and Lopez-Bescos, L., Proceedings of the Royal Society of Medicine, 1968, 61, 1115.

10 Miller, G. A. H., Paneth, M., and Gibson, R. V., British Medical Fournal, 1968, 3, 537.

\section{Suppurative Thrombophlebitis}

The veins have served medicine and the physician well. Though the days when the apothecary-physician lined his purse from the proceeds of phlebotomy have long since gone, not a day now passes without millions of venepunctures being performed for many different reasons. Fortunately a single venepuncture with a needle and the withdrawal of blood rarely has any serious complications. Bruising, haemorrhage, and mild phlebitis can occur but are uncommon if the procedure is expertly performed.

Complications follow venepuncture when foreign substances are injected and when the means of injection-needle or catheter-is left in place for longer than a few minutes. ${ }^{1-3}$ Most substances that we inject into veins have a $\mathrm{pH}$, temperature, and osmolality different from blood and cause a physical or chemical inflammatory response in the vein wall. The end of a needle and the constant rubbing of a plastic catheter will also cause phlebitis. The incidence of phlebitis and thrombosis increases with the duration of the injury. After six hours many veins show some degree of phlebitis, and after 24 hours almost all have some abnormality varying from slight redness to an acute thrombophlebitis. ${ }^{4-5}$ This is not usually an infected thrombophlebitis, but in these early stages there is the danger of infection developing within the thrombus.

In a recent review of 521 patients treated for burns by longterm intravenous infusions through indwelling cannulae J. M. Stein and B. A. Pruitt ${ }^{6}$ found that $24(4 \cdot 6 \%)$ developed suppurative thrombophlebitis after 2-10 days of cannulation. The accompanying septicaemia caused the death of seven of these patients and was believed to be an important contributory cause of the death of another seven. In many of these patients the suppuration in the vein was silent and the first indication of infection was the septicaemia. In less than half were there local signs such as redness, tenderness, and a watery exudate at the puncture site. Suppurative thrombophlebitis must therefore always be remembered as a cause of septicaemia even though there are no localizing signs and even when there-are other possible sources of infection.

Stein and Pruitt recommend excision of the superficial vein if it is believed to be the cause of the septicaemia. They treated 10 patients in this way and only one died. This patient had both long saphenous veins excised in the groins, but the infected thrombus extended into the iliac veins. This em- phasizes the problem of the surgical treatment. A cure can be achieved only if the excision can be complete. This is possible when a short segment of a superficial vein is affected but not when the infected thrombus is in a large trunk vein. Most intensive-care units give long-term intravenous infusions through long catheters which pass from the superficial veins into the large veins of the abdomen and chest. The object of this is to avoid thrombosis, but in fact the blood in these large veins does sometimes undergo thrombosis, and the catheters always develop a layer of thrombus on their surface. This can become infected and produce emboli.

Thus septic thrombophlebitis should be remembered as a possible hazard of inserting needles or cannulae into veins. If it occurs it must be treated thoroughly with the appropriate antibiotics, and, if the area of thrombous is limited, excision of the vein may be beneficial. Phlebography might help to delineate the upper limit of the thrombosis. When the thrombus is beyond surgical reach the catheter should be withdrawn and the antibiotics continued, unless the patient's life depends on intravenous medication. These patients present enormous problems of management, .for the antibiotics are often not effective and death from septicaemia follows.

Can this complication be prevented? An aseptic technique during cannulation is essential, but the administration of local or parenteral antibiotics for prophylaxis is not advisable. The most effective prophylaxis is the restriction of long-term cannulation to a minimum. In many cases daily venepunctures in different veins for the administration of normal fluid requirements is adequate. Arm veins should always be used when possible, and the passage of catheters into the great veins should be restricted to those patients with few superficial veins in whom long-term intravenous therapy is mandatory.

1 Bogen, J. E., Surgery, Gynaecology and Obstetrics, 1960, 110, 112.

2 Hästbacka, J., et al., Acta Anaesthia Scandinavica, 1965, 10, 9.

Elving, G., Hastbacks, J., and Tammisto, T., American Heart fournal, $1967,73,717$.

- Gray, T. C., British Medical fournal, 1967, 1, 107

Thomas, E. T., Evers, W., and Racz, G. B., Anaesthesia and Analgesia Current Researches, 1970, 49, 150.

Stein, J. M., and Pruitt, B. A., New England Fournal of Medicine, 1970, 282, 1452 .

\section{Inquire Within}

One of the smaller but none the less useful benefits of belonging to the B.M.A. comes in its Members Handbook. Unlike many self-styled handbooks this one can be comfortably held in one hand. And perhaps its small stature combined, it must be admitted, with the plainly informative nature of its contents is responsible for its being overlooked more than it should be.

As well as giving much information on the B.M.A.-its functions, publications, policy decisions, and so on-the Handbook also offers advice on many problems that may puzzle or worry doctors in practice. A substantial section is concerned, for instance, with medical ethics, and as well as giving practical guidance it sets out in full the restatement of the Hippocratic Oath embodied in the Declaration of Geneva and the code on human experimentation now known as the Declaration of Helsinki. Other sections give information on financial matters, including superannuation. In short, though the Handbook cannot be described as either compulsive or compulsory reading, it does offer a helpful guide to some of the common problems of medical practice-and it is sent to members free. 